\title{
Quality of life in acromegaly and the association with the clinical parameters of the disease
}

\begin{abstract}
Background: Quality of life is currently considered a major factor in the assessment of disease outcome. Most patients with acromegaly present with skin, bone and soft tissue alterations, as well as hypertension, diabetes mellitus and other cardiovascular symptoms and all these affect patient's mood, personality, interpersonal relationships and social behavior. The aim of this study was to assess quality of life in acromegaly and the association with the clinical characteristics of the disease.
\end{abstract}

Methods: This cross-sectional study included a total of 101 (45 male, 56 female) patients with acromegaly, mean age $59.51 \pm 1.35$ years (mean \pm SEM), with a disease duration of $12.88 \pm 0.96$ years. All subjects completed the Acromegaly Quality of Life Questionnaire (AcroQoL).

Results: Total (mean \pm SEM) score was $86.15 \pm 1.37$ (min22-max110), psychological parameters score was $54.98 \pm 0,95$ ( $\min 14-\max 70$ ), appearance score was $25.95 \pm 0.54$ (min 7 -max 35$)$, personal relationship score was $29.37 \pm 0.52(\min 7-\max 35)$ and finally physical parameters score was $30.93 \pm 0.58(\min 8-\max 40)$. Women and older patients showed slightly worse scores. Patients with macroadenomas, those who received radiotherapy, and those with comorbidities appeared with less mean total QoL scores.

Conclusion: The assessment of quality of life is a critical end point in the management of acromegaly and improvement of quality of life is a major aim in the therapeutic management of acromegaly.

Keywords: Acromegaly, quality of life, growth hormone, igf-1, spss, statistical package for the social sciences
Volume 4 Issue I - 2017

\author{
Dimitrios Kaldrymidis,' Georgios Papadakis, ${ }^{2}$ \\ Georgios Tsakonas, ', Ifigenia Kostoglou- \\ Athanassiou, ${ }^{3}$ Philippos Kaldrymidis, ${ }^{4}$ \\ Melpomeni Peppa, ${ }^{4}$ Paraskevi Roussou, \\ Evanthia Diamanti-Kandarakis ${ }^{5}$ \\ 'Department of Internal Medicine, University of Athens, Sotiria \\ General Hospital, Greece \\ ${ }^{2}$ Department of Endocrinology, Metaxa Anticancer Hospital, \\ Greece \\ ${ }^{3}$ Department of Endocrinology, Red Cross Hospital, Greece \\ ${ }^{4}$ Department of Internal Medicine Propaedeutic, Attikon \\ University Hospital, Medical School, National and Kapodistrian \\ University of Athens, Greece \\ ${ }^{5}$ Endocrinology and Diabetes Unit, Euroclinic Hospital, Greece
}

\begin{abstract}
Correspondence: Georgios Papadakis, Department of Endocrinology, Metaxa Anti-Cancer Hospital, Piraeus, Greece, Botasi 5I, 18537, Pireaus, Athens, Greece, Tel +30 2132079670, Email george.papadakis.md@gmail.com
\end{abstract}

Received: September 06, 2016 | Published: February 20, 2017
Abbreviations: GH, growth hormone; IGF-1, insulin-like growth factor

\section{Introduction}

Excessive growth hormone $(\mathrm{GH})$ and insulin-like growth factor (IGF-1) concentrations in acromegaly cause alterations in body and facial appearance, which are accompanied by effects on major organs, such as the heart and the liver. ${ }^{1,2}$ Successful therapy decreases symptoms related to GH excess such as soft tissue swelling. ${ }^{3}$ Nevertheless, other acromegalic characteristics remain due to permanent changes, for example, in cartilage and bone. Chronic effects of excessive GH secretion are not only disabling but also disfiguring. ${ }^{4}$ Most patients with acromegaly present with a long history of skin, bone and soft tissue alterations, as well as hypertension, diabetes mellitus and other cardiovascular symptoms. ${ }^{5}$ Acromegaly affects a patient's mood, personality, interpersonal relationships and social behavior and has a heavy impact on quality of life. ${ }^{4}$

In many patients biochemical disease control is achieved and morbidity and mortality is restored with current therapeutic advances. ${ }^{5}$ Biochemical control does not mean absolute health restoration from the patients' perspective, since their health-related quality of life may remain reduced. The treatment of acromegaly includes diverse treatment modalities that are long-lasting and may have adverse effects. ${ }^{3}$ In many patients surgery and radiotherapy do not lead to disease control and medical treatment is necessary to control the disease. Somatostatin analogues are frequently administered to control the disease. ${ }^{6}$ Quality of life in acromegaly was investigated in a cohort of patients with acromegaly.

\section{Materials and methods}

In this cross-sectional study, 101 patients with acromegaly were evaluated. All the patients were asked to visit our clinic in 2015 in order to fill in the questionnaire. Moreover, we included all the personal data derived retrospectively from patient charts visiting our clinic over the last 20 years. All patients who were diagnosed with acromegaly were included in the study. Patients were treated and followed up at the Department of Endocrinology of a tertiary medical center in Athens during the years 1995-2015. The study was approved by the local ethical committee. All patients signed an informed consent before entering the study. Demographic characteristics and a medical history, which included history of surgery and radiotherapy, medical treatment, disease duration and pituitary function, were recorded in all patients. Patients were asked to fill in the AcroQol questionnaire. In all patients with confirmed disease, GH and IGF-1 levels were measured. GH levels were measured before and after a glucose tolerance test. All patients were biochemically controlled when they visited our clinic to fill in the AcroQol questionnaire, $\mathrm{GH}$ being $<0.4 \mu \mathrm{g} / \mathrm{L}$ and IGF-1 being within 2 SD of the mean of an age and gender adjusted standardized sample after the administration of a glucose load. 
Patients were requested to complete a questionnaire on quality of life. Acromegaly Quality of Life Questionnaire (AcroQoL) is a diseasespecific questionnaire that assesses quality of life in patients with Acromegaly. ${ }^{7}$ It contains 22 questions with five possible responses. Each response is scored from 1 to 5 on the basis of frequency of occurrence (ranging from always to never) and degree of agreement with the points (ranging from completely agree to completely disagree). The maximum score is 110 points $(100 \%)$, whereas the minimum score is $22(0 \%)$. It is divided into 2 scales that measure physical (AcroPhy) (eight items) and psychological parameters (AcroPsy). The latter is further subdivided into 2 subcatgories: the appearance (AcroApp) (seven items) and the personal relationships (AcroRel) (seven items). ${ }^{7,8}$ AcroQol questionnaire was translated to Greek language for the present study.

Statistical analysis was performed with the Statistical Package for the Social Sciences (SPSS, Chicago, IL; USA) (version 19.0). Values are presented as mean \pm SEM for continuous variables and as frequencies (percentage) for categorical data. Differences between biochemically controlled and uncontrolled patients for demographic variables were analyzed using chi square tests, repeated measures analysis of variance, and independent samples $t$-test.

\section{Results and discussion}

A total of 101 patients with acromegaly were assessed, 45 male, 56 female, mean age $59.51 \pm 1.35$ years, with a mean disease duration of $12.88 \pm 0.96$ years. Mean age at diagnosis was $46.63 \pm 1.31$ years. A total of 38 patients had a microadenoma (tumors less than or equal to $10 \mathrm{~mm}$ ) and 63 patients had a macroadenoma (tumors exceeding $10 \mathrm{~mm}$ ). All patients were biochemically controlled when they filled in the questionnaire. Of the patients treated with somatostatin analog therapy, a group of 27 patients was treated initially with a somatostatin analogue s.c. in 3 divided daily doses as a primary treatment with mean duration of $4.58 \pm 3.12$ years and subsequently long acting somatostatin analogues i.m. once every 28 days, whereas 72 were treated with long acting somatostatin analogues i.m. once every 28 days as a primary medical treatment with mean duration of $12.26 \pm 9.61$ years. Only 2 patients were successfully treated with surgical therapy and received no medical treatment afterwards. Additionally, 31 patients were treated with pegvisomant and 6 patients with dopamine agonists. A group of 79 patients underwent pituitary surgery, 12 of them underwent additional radiotherapy, and 1 patient was treated only with radiotherapy. Hypopituitarism after pituitary surgery was treated with hormonal replacement therapy in 16 patients. The descriptive characteristics of patients are presented in Table 1. AcroQol scores are shown in Table 2.

AcroQoL scores between genders were also compared. Total Qol score after treatment with long acting somatostatin analogues was $87.57 \pm 1.94$ (mean \pm SEM) and $85.02 \pm 1.92$ in men and women, respectively, $\mathrm{p}=0.625$, Student's t test, Psychological QoL score was $56.02 \pm 1.35$ and $54.15 \pm 1.33$, in men and women, respectively, $\mathrm{p}=$ 0.865 , and Physical QoL was $31.45 \pm 0.77$ and $30.51 \pm 0.84$, in men and women, respectively, $\mathrm{p}=0.152$. Women showed slightly worse scores, but the difference was not statistically significant.

Patients who received radiotherapy had a score of $79.23 \pm 4.46$ $(m e a n \pm S E M)$ whereas those who did not had a score of $87.20 \pm 1.4$, respectively, $p=0.434$, Student's t-test. Patients with a microadenoma had different mean total QoL score as opposed to those with macroadenoma. Patients with microadenomas and macroadenomas had scores of $87.68 \pm 1.99$ and $85.24 \pm 1.83$, respectively, $\mathrm{p}=0.196$. Patients younger than 60 years old $(n=52)$ had different mean total QoL score than patients older than 60 years old $(n=47), 86.94 \pm 1.89$ as opposed to $85.28 \pm 2.0$, respectively, $\mathrm{p}=0.966$. Patients with disease duration of less than 12 years $(n=50)$ had also different total QoL scores after treatment with long acting somatostatin analogues than those with disease duration longer than 12 years $(n=49), 87.28 \pm 1.87$ as opposed to $85.0 \pm 2.01$, respectively, $\mathrm{p}=0.971$.

Table I Descriptive characteristics of patients with acromegaly

\begin{tabular}{ll}
\hline Variable & Number of patients $(\mathbf{n = 1 0 1})$ \\
\hline Age (years \pm SEM) & $59.51 \pm 1.35$ \\
Age at Diagnosis (years \pm SEM) & $46.63 \pm 1.31$ \\
Males / females & $45 / 56$ \\
Micro/macroadenoma & $38 / 63$ \\
Surgical therapy & 79 \\
Radiotherapy & 13 \\
Medical therapy & 99 \\
Hypertension & 52 \\
Cardiovascular disease & 15 \\
Diabetes Mellitus & 51 \\
Malignancies & 16 \\
\hline
\end{tabular}

Table 2 AcroQol scores (mean \pm SEM) in patients with Acromegaly

\begin{tabular}{ll}
\hline Variable & Total score \\
\hline AcroTot $(\min 22-\max 110)$ & $86.15 \pm 1.37$ \\
AcroPsy $(\min 14-\max 70)$ & $54.98 \pm 0.95$ \\
AcroApp $(\min 7-\max 35)$ & $25.95 \pm 0.54$ \\
AcroRel $(\min 7-\max 35)$ & $29.37 \pm 0.52$ \\
AcroPhy $(\min 8-\max 40)$ & $30.93 \pm 0.58$
\end{tabular}

Patients with comorbidities showed different mean total QoL scores after treatment with long acting somatostatin analogues, however, the difference was not statistically significant. Thus, acromegalic patients exhibiting diabetes mellitus had a total QoL score of $83.68 \pm 1.97$ (mean \pm SEM) as opposed to those not exhibiting diabetes mellitus having $88.67 \pm 1.86, \mathrm{p}=0.656$. Acromegalic patients with arterial hypertension had a total QoL score of $82.73 \pm 1.9$ as opposed to those without having $89.94 \pm 1.8, \mathrm{p}=0.620$. Patients with acromegaly and hypopituitarism after surgery had a total QoL score of $83.40 \pm 3.95$ as opposed to those without hypopituitarism having $86.64 \pm 1.46$, $\mathrm{p}=0.814$. Acromegalic patients with concomitant cardiovascular disease had a total QoL score of $78.80 \pm 4.17$ as opposed to those without cardiovascular disease having $87.46 \pm 1.40, \mathrm{p}=0.483$. Patients with acromegaly and malignancy had a total QoL score of $83.20 \pm$ 3.36 as opposed to those with patients without malignancy having $86.68 \pm 1.5, \mathrm{p}=0.933$. 
The aim of the present study was to evaluate quality of life in patients with acromegaly and all the clinical parameters that are related to it. Acromegaly affects all organ systems and some of the alterations induced may be permanent, as are those on bone. Additionally, acromegaly affects the cardiovascular system causing arterial hypertension and cardiac hypertrophy. Acromegaly is often accompanied by sleep apnea and its complications. The patient's appearance is affected causing psychological problems and difficulties in interpersonal relationships. Additionally, treatment may not reverse some of the alterations, thus there may not exist an association between GH and IGF-1 levels and subjective health related quality of life., ${ }^{4,5}$ Acromegaly demands a multifaceted therapeutic approach. ${ }^{9}$ Surgery is the cornerstone of treatment, radiotherapy may be necessary and subsequent medical therapy is often needed. The fundamental role of quality of life in patient-oriented clinical approach has long been recognized by the World Health Organization. ${ }^{10}$ Quality of life is an important element in order to improve patient management ${ }^{11}$ and it is crucial to place greater emphasis on the role of psychology of the patient in acromegaly.

In our study macroadenomas, older age, history of radiotherapy and comorbidites are associated with with a lower mean score in AcroQol questionnaire; the differences, however, are slight, and in no cases reached statistical significance at $p<0.05$. Radiotherapy may be associated with detrimental effects on the brain ${ }^{12}$ and could possibly affect quality of life, and this is worse with the coexistence of pituitary deficiency. ${ }^{13}$ Radiotherapy has been associated with worse quality of life in previous studies. ${ }^{4,14,15}$ Pituitary deficiency negatively affects quality of life. ${ }^{16}$ Persistent comorbidities impair quality of life in acromegaly. ${ }^{17}$ Moreover, an association was observed in the present study between disease duration and poorer quality of life [to the authors: that is not demonstrated in this study; difference was not statistically significant]. Similar results are reported from other studies. $^{18}$

Regarding gender, women showed slightly worse scores in our study, although the difference was not statistically significant. According to published studies men had better quality of life in some studies, ${ }^{4,16,19}$ whereas others show opposite results. ${ }^{5,20,21}$ In our study younger patients had slightly higher quality of life scores, but again, these failed to reach statistical significance. Previous studies showed that younger age was associated with better quality of life $\mathrm{e}^{14}$ and negative influence of age has been reported, ${ }^{5}$ whereas other studies have found no relationship., ${ }^{4,16,21,22}$ In a recent Japanese study young age and previous radiotherapy were found to be associated with lower quality of life $\mathrm{e}^{23}$ Our study has also some limitations such as it is a study from a single Greek center and the relative small number of patients which is a reason for not finding statistical significance difference in many parameters. Nevertheless, acromegaly is a rare disease and most studies include small cohorts of patients.

\section{Conclusion}

In conclusion, it appears that the assessment of quality of life is a critical end point in the management of acromegaly, improvement of quality of life being a major aim in the therapeutic management of acromegaly.

\section{Acknowledgments}

None.

\section{Conflicts of interest}

The author declares there is no conflict of interest.

\section{References}

1. Katznelson L, Laws ER, Melmed S, et al. Acromegaly: an endocrine society clinical practice guideline. J Clin Endocrinol Metab. 2004;99(11):3933-3951.

2. Cuevas-Ramos D, Carmichael JD, Cooper O, et al. A structural and functional acromegaly classification. J Clin Endocrinol Metab. 2015;100(1):122-131.

3. Giustina A, Chanson P, Kleinberg D, et al. Expert consensus document: A consensus on the medical treatment of acromegaly. Nat Rev Endocrinol. 2014;10(4):243-248.

4. Pantanetti P, Sonino N, Arnaldi G, et al. Self image and quality of life in acromegaly. Pituitary. 2002;5(1):17-19.

5. Holdaway IM, Rajasoorya RC, Gamble GD. Factors influencing mortality in acromegaly. J Clin Endocrinol Metab. 2004;89(2):667-674.

6. Howlett TA, Willis D, Walker G, et al. Control of growth hormone and IGF1 in patients with acromegaly in the UK: responses to medical treatment with somatostatin analogues and dopamine agonists. Clin Endocrinol (Oxf). 2013;79(5):689-699.

7. Webb SM, Prieto L, Badia X, et al. Acromegaly Quality of Life Questionnaire (ACROQOL) a new health-related quality of life questionnaire for patients with acromegaly: development and psychometric properties. Clin Endocrinol (Oxf). 2002;57(2):251-258.

8. Badia X, Webb SM, Prieto L, et al. Acromegaly Quality of Life Questionnaire (AcroQoL). Health Qual Life Outcomes. 2004;2:13.

9. Roelfsema F. Treatment of Acromegaly: Are We Satisfied With the Current Outcome? Ebio Medicine. 2015;2(1):5-6.

10. Webb SM, Badia X, Surinach NL. Validity and clinical applicability of the acromegaly quality of life questionnaire, AcroQoL: a 6-month prospective study. Eur J Endocrinol. 2006;155(2):269-277.

11. Biermasz NR, van Thiel SW, Pereira AM, et al. Decreased quality of life in patients with acromegaly despite long-term cure of growth hormone excess. J Clin Endocrinol Metab. 2004;89(11):5369-5376.

12. Peiffer AM, Leyrer CM, Greene-Schloesser DM, et al. Neuroanatomical target theory as a predictive model for radiation-induced cognitive decline. Neurology. 2013;80(8):747-753.

13. Maric NP, Doknic M, Pavlovic D, et al. Psychiatric and neuropsychological changes in growth hormone-deficient patients after traumatic brain injury in response to growth hormone therapy. J Endocrinol Invest. 2010;33(11):770-775.

14. Kauppinen-Makelin R, Sane T, et al. Quality of life in treated patients with acromegaly. The Journal of clinical endocrinology and metabolism. 2006;91(10):3891-3896.

15. van der Klaauw AA, Biermasz NR, Hoftijzer HC, et al. Previous radiotherapy negatively influences quality of life during 4 years of follow-up in patients cured from acromegaly. Clin Endocrinol (Oxf). 2008;69(1): $123-128$.

16. T'Sjoen G, Bex M, Maiter D, et al. Health-related quality of life in acromegalic subjects: data from AcroBel, the Belgian registry on acromegaly. Eur J Endocrinol. 2007;157(4):411-417.

17. Psaras T, Milian M, Hattermann V, et al. Predictive factors for neurocognitive function and Quality of Life after surgical treatment for Cushing's disease and acromegaly. J Endocrinol Invest. 2011;34(7):e168-e177. 
18. Siegel S, Streetz-van der Werf C, et al. Diagnostic delay is associated with psychosocial impairment in acromegaly. Pituitary. 2013;16(4):507514.

19. Anagnostis P, Efstathiadou ZA, Charizopoulou M, et al. Psychological profile and quality of life in patients with acromegaly in Greece. Is there any difference with other chronic diseases? Endocrine. 2014;47(2):564 571.

20. Rowles SV, Prieto L, Badia X, et al. Quality of life (QOL) in patients with acromegaly is severely impaired: use of a novel measure of QOL: acromegaly quality of life questionnaire. J Clin Endocrinol Metab. 2005;90(6):3337-3341.
21. Kepicoglu H, Hatipoglu E, Bulut I, et al. Impact of treatment satisfaction on quality of life of patients with acromegaly. Pituitary. 2014;17(6):557563.

22. Biermasz NR, Pereira AM, Smit JW, et al. Morbidity after long-term remission for acromegaly: persisting joint-related complaints cause reduced quality of life. J Clin Endocrinol Metab. 2005;90(5):2731-2739.

23. Yoshida K, Fukuoka H, Matsumoto R, et al. The quality of life in acromegalic patients with biochemical remission by surgery alone is superior to that in those with pharmaceutical therapy without radiotherapy, using the newly developed Japanese version of the AcroQoL. Pituitary. 2015;18(6):876-883. 